\title{
ANÁLISE DO TURISMO DE AVENTURA NO MUNICÍPIO DE QUIXADÁ (CEARÁ-
}

BRASIL)

Iana Barbara Oliveira Viana Lima1

Universidade Federal do Ceará

ianaviana07@hotmail.com

Prof. Dr. Edson Vicente da Silva²

Universidade Federal do Ceará

cacauceara@gmail.com

Prof. Dr. Laura Mary Marques Fernandes ${ }^{3}$

Universidade Estadual do Ceará

lauralucas66@hotmail.com

Prof. Dr. Carlos Henrique Sopchaki ${ }^{4}$

Universidade Federal do Ceará

carlos.geografia@ufc.br

Para citar este artículo puede utilizar el siguiente formato:

lana Barbara Oliveira Viana Lima, Edson Vicente da Silva, Laura Mary Marques Fernandes y Carlos Henrique Sopchaki: "Análise do turismo de aventura no município de Quixadá (Ceará-Brasil)", Revista Turydes: Turismo y Desarrollo, n. 29 (diciembre/dezembro 2020). En línea:

https://www.eumed.net/es/revistas/turydes/vol-13-no-29-diciembre-dezembro-2020/turismo-aventura-quixada

Resumo

O Turismo de Aventura é um segmento que tem como característica o maior contato e interação com a natureza, através de atividades de aventura estimulantes e não competitivas. A pesquisa tem como principal objetivo conhecer a dinâmica do Turismo de Aventura no município de Quixadá, identificando as atividades que são desenvolvidas, os núcleos de concentração dessas atividades e sua infraestrutura, os atrativos geoturísticos do município, suas limitações e potencialidades. A pesquisa se fundamenta na Geoecologia das Paisagens, sistematizada em quatro fases: Organização e Inventário; Análise; Diagnóstico e Prognóstico. Identificou-se que existe a concentração do turismo de aventura em alguns pontos do município, além de alguns problemas e limitações. 
Palavras-chave: Quixadá; geodiversidade; turismo de aventura; Ceará.

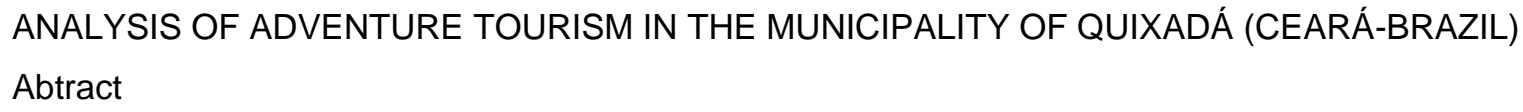

Adventure Tourism has a characteristic with greater contact and interaction with nature, through stimulating adventure activity withour competitiveness. The objective of research is to determine the limitations and potential based on dynamics of Adventure Tourism in the municipality of Quixadá, such as tourism activities, the centers of these activities, other tourist attractions of the area and its infrastructure. The research is conducted based on Geoecology of Landscapes which systematized in four stages: organization and inventory; analysis; diagnosis and prognosis. As a result, a concentration of adventure tourism in some parts of the city was identified in addition to other problems and limitations.

Keywords: Quixadá; geodiversity; adventure tourism, Ceará.

\section{ANÁLISIS DEL TURISMO DE AVENTURA EN EL MUNICIPIO DE QUIXADÁ (CEARÁ-BRASIL)}

\section{Resumen}

El turismo de aventura es un segmento que tiene como característica el mayor contacto e interacción con la naturaleza, a través de actividades de aventura estimulantes y no competitivas. La investigación tiene como objetivo principal conocer la dinámica del Turismo de Aventura en la ciudad de Quixadá, identificando las actividades que se desarrollan, los centros de concentración de estas actividades y su infraestructura, los atractivos geoturísticos de la ciudad, sus limitaciones y potencialidades. La investigación se basa en la Geoecología de los Paisajes, sistematizada en cuatro fases: Organización e inventario; análisis; diagnóstico y pronóstico. Se identificó que hay una concentración de turismo de aventura en algunos puntos de la ciudad, además de algunos problemas y limitaciones.

Palabras clave: Quixadá; geodiversidad; turismo de aventura, Ceará.

\section{Introdução}

No final do século $X X$ se intensificam os debates referentes à problemática ambiental e aos impactos resultantes da interação entre o turismo e o meio ambiente, refletindo-se no surgimento de novas alternativas para se planejar o desenvolvimento turístico de forma mais contextualizada à importância da preservação ambiental e fundamentado nos pilares do desenvolvimento sustentável (sociedade, natureza e economia), tendo como princípios norteadores: atender as necessidades dos turistas, satisfazer os interesse do viés econômico e considerar a importância da preservação ambiental, como forma de assegurar a qualidade de vida das gerações futuras (Swarbrooker, 2000). 
Múltiplos segmentos com enfoque ambiental surgem nas últimas décadas, influenciados pela mudança de perspectivas do turismo e, principalmente, relacionado às exigências da demanda, pois nota-se que há uma tendência cada vez maior na busca por experiencias mais empíricas com a natureza, experiencias que ultrapassam o mero caráter contemplativo da paisagem e o proporcionam atividades mais próximas com o meio ou mesmo como forma de auto conhecimento e fuga dos centros urbanos (Dantas e Pires, 2015).

O turismo de aventura é um dos segmentos que afloram nesse contexto e pode ser compreendido como um segmento decorrente da oferta de atividades recreativas que envolvem aventura e pode ser realizado em ambientes urbanos, rurais, naturais, construídos e demais (Brasil, 2010). Embora o segmento possa ser desenvolvido em variados espaços, no Brasil há uma tendência do mesmo em manifestar-se em espaços nos notada proximidade com a natureza.

Diante da proximidade entre o turismo de aventura e o meio ambiente, o estado do Ceará, localizado na região Nordeste do Brasil, se configura como um importante destino para a efetivação do segmento, em virtude do seu potencial ambiental e de suas paisagens litorâneas, sertanejas e serranas. O turismo de aventura é um dos principais segmentos turísticos que se desenvolve no estado, juntamente com o turismo ecológico, turismo de sol e praia, turismo cultural e científico, turismo religioso, turismo de negócios e eventos e turismo rural.

No estado existem diversos destinos de turismo de aventura e para o desenvolvimento desta pesquisa, adotou-se como área de estudo o município de Quixadá, localizado na região semiárida do Ceará e um local de relevante destaque para o segmento, especialmente em relação à prática do voo livre (parapente e asa delta). Quixadá é reconhecido internacionalmente pelo público desse segmento em virtude dos recordes mundiais de voo. Ainda são desenvolvidas demais atividades do turismo de aventura, como caminhadas, escaladas, espeleoturismo, cicloturismo e outras.

A escolha em trabalhar com a área também foi motivada pela importância de valorizar e divulgar as potencialidades turísticas das regiões semiáridas do estado, pois mesmo o Ceará sendo um dos principais destinos turísticos nacionais, há a concentração de fluxos turísticos e de investimentos nas áreas litorâneas, deixando de contemplar demais espaços que possuem potencial e que necessitam de estratégias de desenvolvimento local.

O objetivo principal da pesquisa é reconhecer como o turismo de aventura se desenvolve no município de Quixadá, os locais onde se concentram a oferta de atividades, as atividades que são realizadas, os geoatrativos ambientais da área, os problemas ligados ao segmento, as suas limitações e as suas potencialidades.

A metodologia escolhida para a efetivação da pesquisa é a Geoecologia das Paisagens, pois acredita-se que sua perspectiva sistêmica é capaz de alcançar toda a dinamicidade inerente ao turismo. A estrutura da pesquisa encontra-se sistematizada nas quatro fases propostas pela 
Geoecologia das Paisagens: Fase de Organização e Inventário, Fase de Análise, Fase de Diagnóstico e Fase de Prognóstico.

\section{Referencial teórico}

\subsection{Concepções sobre o turismo de aventura}

Desde os primórdios históricos, as comunidades humanas têm estabelecido relações com o meio em que se desenvolvem, tanto com a biodiversidade (fauna e flora), quanto com a geodiversidade (geomorfologia, clima, solos e demais), conferindo-lhes valores e usos que estão relacionados com as mais variadas vertentes culturais, estéticas, funcionais e econômicas (Brilha, 2005; Borba, 2010).

A forma como a humanidade se relaciona com o meio ambiente têm gerado impactos negativos para a natureza, como poluição, desgaste dos recursos naturais, desequilíbrio de ecossistemas, extinção de espécies animais e outros. Diante dos impactos negativos, novas estratégias de desenvolvimento foram surgindo nos mais variados segmentos da sociedade, entre eles, o turismo. A partir da década de 1970, afloram segmentos turísticos influenciados pela perspectiva ambiental e que consideram a geodiversidade como um potencial atrativo turístico (Moreira, 2014).

O turismo de aventura é um dos segmentos que tem como principais atrativos os elementos da geodiversidade, nascendo em meio aos questionamentos e reflexões em torno de um desenvolvimento turístico com perspectivas e significados influenciados pelos preceitos da conservação ambiental, redirecionando as formas de convivência com o meio ambiente.

Serrano e Ruiz-Flaño (2007) define a geodiversidade como a natureza abiótica, formadas pelos elementos litológicos, tectônicos, geomorfológicos, edáficos, hidrológicos, topográficos e todos os processos físicos existentes na superfície terrestre e marinha, incluindo os sistemas oriundos de processos naturais, endógenos, exógenos e antrópicos.

Além dos elementos geológicos e geomorfológicos, o conceito de geodiversidade alcança demais componentes abióticos da natureza, como topografia, hidrologia, solos e a própria dinâmica interna e externa do planeta, considerando as múltiplas manifestações geológicas (Serrano et al., 2007; Pereira, Rios e Garcia, 2016).

A geodiversidade como potencialidade no cenário turístico eleva-se de forma mais acentuada a partir do século XXI, reforçada pelo surgimento de segmentos que estão intrinsecamente relacionados com os atrativos ambientais, como o ecoturismo, turismo rural, turismo de aventura e geoturismo, fazendo com que a geomorfologia, como ciência aplicada, adentre em novas abordagens de pesquisas, entre elas, o turismo, através do enfoque geológico e geomorfológico, valorizando cenários como cavernas, montanhas, fontes termais, rios, cânions e outros (Moreira, 2014).

O turismo de aventura apresenta considerável crescimento ao longo dos anos e se destaca entre os outros segmentos que compartilham da mesma concepção integrada com a natureza, despertando o interesse da demanda que anseia por atividades estimulantes e distintas do turismo convencional (Swarbrooker, 2003). 
Embora seja frequentemente associado com o ecoturismo, existem diferenças entre ambos. Dentre as diferenças entre o turismo de aventura e o ecoturismo, destaca-se principalmente a forma como o turista se relaciona com o meio. Nos dois segmentos o turista vivência a interação com a natureza, no entanto, no turismo de aventura essa interação ocorre por meio de atividades que envolvem adrenalina e risco controlado (Coriolano e Morais, 2011).

Diante de seu desenvolvimento, o turismo de aventura foi adquirindo particularidades que 0 diferenciava do ecoturismo, como o perfil da demanda, a oferta de atividades distintas, as motivações que impulsionam a sistematização do segmento, a realização de eventos voltados para a sua promoção e divulgação, resultando no surgimento de um segmento específico.

De acordo com o Ministério do Turismo do Brasil, o "Turismo de Aventura compreende os movimentos turísticos decorrentes da prática de atividades de aventura de caráter recreativo e não competitivo" (Brasil, 2010, p. 19). O segmento é dividido nas categorias terra, água e ar, contendo um grupo de atividades associada a cada categoria, classificadas de acordo com o Ministério do Turismo do Brasil.

O segmento é promissor, pois permite ao turista maior contato com o meio ambiente, através de atividades desafiadoras e com risco controlado, planejadas para proporcionar divertimento e segurança. Percebe-se que o turismo de aventura se diferencia do turismo tradicional, pois nele, a natureza não é apenas contemplada, mas vivenciada.

Mesmo existindo variadas definições para o turismo de aventura, todas se complementam e a base fundamental que sustenta 0 conceito desse segmento envolve os preceitos da sustentabilidade ambiental e o prazer em experienciar práticas turísticas que proporcionam maior interação com a natureza (Vasconcelos, Silva e Costa, 2012).

Considerando as transformações nas ofertas turísticas e o interesse do público por experiencias inovadoras, se identifica o aumento da demanda nacional e internacional do segmento no Brasil, fazendo do turismo de aventura um dos segmentos prioritários no direcionamento de investimentos que assegurem a sua organização e estrutura (Brasil, 2010).

O contexto ambiental brasileiro é atrativo ao turista e o turismo de aventura encontra as condições propícias que favorecem o seu crescimento e desenvolvimento, destacando-se múltiplos destinos no país, presentes nas mais variadas regiões e com a oferta de atividades que valorizam as potencialidades de cada área. Diante do potencial existente, o turismo de aventura intensifica-se no país a partir da década de 1990.

Esse período é de fundamental importância para o desenvolvimento do turismo de aventura no Brasil, pois se inicia a confecção dos primeiros equipamentos para o segmento, como cordas, capacetes e caiaques infláveis. O primeiro evento acontece em 1999, a Adventure Sports Fair, de grande importância para a divulgação e conhecimento sobre as particularidades do segmento, além de sua importância para estimular o surgimento de associações de turismo de aventura, contribuindo para a sua sistematização. (Brasil, 2010).

Entre as regiões nacionais, o Nordeste é um polo favorável ao turismo de aventura e o Ceará é um dos estados que se sobressaem como importante destino para o segmento, alcançando 
projeção nacional e internacional. O segmento é um dos principais do estado, juntamente com os segmentos sol e praia, natureza e ecoturismo.

A geodiversidade encontrada no Ceará se configura como importante potencial para o desenvolvimento do turismo de aventura, dispondo de atividades como escalada, voo livre, caminhada, kitesurf, cavalgada, tirolesa, cicloturismo, espeleoturismo, entre outros. Esse segmento turístico encontra-se presente nas três principais paisagens do estado: (i) Planície Litorânea, nos municípios Aracati, Jijoca de Jericoacoara e Caucaia; (ii) Depressão Sertaneja, nos municípios de Jardim, Quixadá e Sobral e (iii) Maciços Residuais, nos municípios Tianguá, Viçosa do Ceará e Ubajara.

Todos esses destinos estão inseridos na dinâmica do turismo de aventura e alguns possuem reconhecimento nacional e internacional em algumas das atividades, por exemplo, o município de Caucaia, conhecido pela prática do kitesurf e o município de Quixadá, conhecido pela quebra de recordes mundiais em saltos de voo livre (parapente e asa delta).

\subsection{O município de Quixadá: a relação entre o turismo de aventura e a geodiversidade}

Quixadá tem extensão territorial de 2.019,82 km², sendo um dos 174 municípios cearenses inseridos no semiárido brasileiro. O município está integrado no Domínio Morfoclimático do Semiárido, seu clima é Tropical Quente Semiárido, com temperatura média que oscila entre $26^{\circ} \mathrm{C}$ e $28^{\circ} \mathrm{C}$ e sua média pluviométrica anual é de aproximadamente $838 \mathrm{~mm}$ com distribuição irregular, concentrada entre os meses de fevereiro a maio (Ceará, 2017).

Dentre as características ambientais, a diversidade de sua geomorfologia é considerada o diferencial, sobretudo em relação aos campos de inselbergs (Figura 1) que simbolizam a principal paisagem do município e um dos atrativos para o desenvolvimento do turismo de aventura, além de ser uma unidade geomorfológica dotada de valores culturais.

A maior superfície de unidade geomorfológica de Quixadá é a Depressão Sertaneja que ocupa considerável área do território. Contudo, a unidade Campos de Inselbergs é a de maior expressividade da geodiversidade por ser a principal característica paisagística do município de Quixadá, conhecido como a "Terra dos Monólitos" em referência a sua beleza cênica, importante característica que impulsiona o turismo local (Lima, Crispim e Souza, 2016).

Em virtude de suas particularidades, de seus valores culturais, paisagísticos e arqueológicos, Quixadá recebeu em 2004 o tombamento de parte de seus Campos de Inselbergs, integrando o total de 5.828,09 ha em sua poligonal, com 13 unidades rochosas, nomeado Conjunto Paisagístico dos Serrotes do município de Quixadá (Silva, 2017; Paiva, Coutinho e Junior, 2006).

A geodiversidade presente em Quixadá possui relevante potencial turístico no semiárido cearense, atraindo visitantes que buscam, além da apreciação da paisagem, vivenciar variadas formas de interação com a natureza, através de atividades de aventura que são associadas à geodiversidade local, sobretudo, referentes ao turismo de aventura. As formações rochosas do município permitem a realização das principais atividades realizadas no município: escaladas, caminhadas com os mais distintos graus de dificuldade e saltos de voo livre (Figura 2). 
Em relação ao voo livre, outro fator preponderante é intensidade e frequência dos ventos no estado, pois ela recebe influência dos ventos alísios e no segundo semestre, a Zona de Convergência Inter Tropical (ZCIT) desloca-se mais para o norte, em relação à sua normal climatológica, fazendo com que, nesse período, haja maior intensidade dos ventos, por isso, no segundo semestre é o melhor período para a realização do voo livre e onde se concentram aos principais eventos da modalidade ( Camelo, Carvalho, Leal-Junior e Accioly-Filho, 2008).

Outro elemento climático que contribuiu para fazer de Quixadá uma referência internacional na prática do voo livre é a temperatura. O calor da caatinga é favorável para a prática do voo livre, pois ao ser aquecido, o ar fica mais leve e facilita a suspensão e manutenção do voo, fazendo com que os pilotos executem voo mais prolongados. Ainda se considera como importante influencia na qualidade do voo, a velocidade dos ventos da região, com aproximadamente $40 \mathrm{~km} / \mathrm{h}$ (Brion, 2016).

Os aspectos geomorfológicos, a dinâmica dos ventos e a temperatura do ar, fazem do município de Quixadá uma das principais regiões no âmbito mundial para a realização do voo livre, resultando em eventos que levaram a quebra de recordes mundiais, atraindo turistas brasileiros e estrangeiros que buscam experiências desafiadoras e a obtenção de recordes pessoais e mundiais. Faz-se importante mencionar que, em razão da dinâmica temporal dos ventos, o período de maior fluxo turístico para a prática do voo livre é de setembro até janeiro (Brion, 2016).

\section{Metodologia}

O embasamento teórico da pesquisa foi fundamentado nos preceitos da Geoecologia das Paisagens, pois credita-se que em função do seu caráter holístico, essa pode ser capaz de apreende a dinamicidade inerente ao fenômeno turístico ao considerar os aspectos sociais e ambientais que atuam no meio ambiente (Rodriguez e Silva, 2013).

O caminho metodológico percorrido foi sistematizado de acordo com as fases propostas pela Geoecologia das Paisagens, organizado em quatro etapas: Organização e Inventário, Análise, Diagnóstico e Prognóstico

$\mathrm{Na}$ fase de Organização e Inventário, foram efetivadas as tarefas gerais preparatórias para o planejamento das etapas da pesquisa, iniciando pelo levantamento bibliográfico, envolvendo temas como geodiversidade, aspectos históricos e conceituais do turismo, segmentação turística e turismo de aventura. Em seguida foi realizado o levantamento de dados secundários referentes aos aspectos históricos, ambientais e sociais da área de pesquisa, com objetivo de conhecer as características do município de Quixadá.

Nessa etapa, foram definidos os parâmetros norteadores para a identificação das atividades de turismo de aventura que são realizadas na área, optando por utilizar a classificação disponibilizada pelo Ministério do Turismo do Brasil, que divide as atividades nas categorias terra, água e ar. Foram iniciados os trabalhos de campo com o principal objetivo de reconhecer a dinâmica da área da pesquisa e elaborar um banco de dados com as informações sobre a caracterização geral do local. 
No final desta etapa, obteve-se uma síntese das informações e dados gerais (históricos, ambientais e sociais) que contribuíram no planejamento dos passos futuros da pesquisa, tendo como principal direcionamento, o alcance dos objetivos propostos.

$\mathrm{Na}$ fase de análise, os trabalhos de campo foram intensificados, juntamente com a aplicação de entrevistas com o público relacionado ao turismo de aventura e outros segmentos turísticos (guias turísticos, instrutores de voo livre, funcionários da rede hoteleira, empreendedores, representantes das secretarias locais e representantes de instituições ambientais). Foi elaborado o material cartográfico de geomorfologia e geologia, usado como embasamento para complementar a análise das unidades geoambientais presentes na área, além de auxiliar na elaboração do diagnóstico e na construção de proposições nas fases posteriores.

A partir dos campos realizados, foi feita a identificação de seis núcleos habitacionais que concentram o desenvolvimento do turismo de aventura no município e posteriormente, foram direcionadas novas visitas de campo para cada núcleo, visando investigar as atividades realizadas, a infraestrutura e demais informações pertinentes ao segmento.

Ao final desta etapa, foi feita a organização e interpretação dos dados e informações reunidos, auxiliando na efetivação da etapa seguinte da pesquisa, servindo como base para a identificação da estrutura do turismo de aventura no município, suas potencialidades e suas limitações.

$\mathrm{Na}$ fase de Diagnóstico, foi traçado um perfil sobre a dinâmica do turismo de aventura, as atividades que são realizadas, os núcleos onde essas se concentram, seus problemas e limitações, além de suas potencialidades. Identificou-se que o segmento não se desenvolve de forma homogênea no município, mas se concentra em seis principais núcleos, deixando de privilegiar demais áreas com relevante interesse turístico. Ainda nessa etapa foram identificados os demais segmentos que se manifestam em cada núcleo, além do turismo de aventura, assim como os atrativos ambientais e culturais, existentes no município.

$\mathrm{Na}$ fase de Prognóstico, com base na identificação e compreensão alcançadas nas fases anteriores, foi elaborado um conjunto de sugestões voltado para os principais problemas identificados e com o objetivo de contribuir positivamente no desenvolvimento do turismo de aventura no município de Quixadá.

\section{Resultado e discussões}

Em razão de sua diversidade ambiental e dos valores culturais, o município de Quixadá se torna um prolífero cenário para a segmentação do turismo que se apresenta em múltiplas vertentes, como o turismo religioso, turismo cultural, turismo científico, turismo de natureza e turismo de aventura, que traçam estratégias de desenvolvimento explorando o potencial local.

Com a efetivação da pesquisa, verificou-se que o turismo de aventura não se desenvolve de forma homogênea no município e que o segmento se concentra em seis núcleos: Sede de Quixadá, Fazenda Magé, Bacia do Cedro, Morro do Urucum-Santuário Rainha do Sertão, Juatama-Hotel Pedra dos Ventos e Serra do Estevão. Cada núcleo manifesta suas próprias especificidades, atrativos, atividades. 
Em relação às particularidades ambientais de Quixadá, constatou-se que a sua geodiversidade está diretamente relacionada com desenvolvimento do turismo de aventura e com a oferta de atividades do segmento, dado que estas necessitam dos elementos da geodiversidade para serem realizadas.

Ao reconhecer as particularidades geomorfológicas e climáticas, juntamente com as condições necessárias para a realização do voo livre, observou-se que a combinação dos elementos naturais é a principal responsável em favorecer a qualidade dos voos realizados na área. Ainda se destaca a importância das condições geomorfológica na realização de trilhas, escaladas e rapel, pois a sua diversidade permite a criação de roteiros com vasta opções de atividades em variados graus de intensidade e duração.

Os seis núcleos de desenvolvimento do turismo de aventura que foram identificados estão inseridos nas áreas de maior expressividade geomorfológica do município. A Sede Quixadá, Fazenda Magé, Bacia do Cedro, Morro do Urucum e Juatama estão localizados em áreas de afloramentos rochosos e campos de inselbergs. O núcleo Serra do Estevão localiza-se em um domínio montanhoso. Sendo assim, no de correr da investigação, observou-se que há uma estreita relação entre o turismo de aventura de Quixadá e a sua geodiversidade.

\subsection{Sede Quixadá}

A sede municipal concentra a oferta de comércio e serviços do município, dispondo de estrutura de apoio ao turismo, como hotéis, pousadas, restaurantes, bares, agências bancárias, agências de turismo, rodoviária e demais ofertas, por isso, esse núcleo assume grande relevância no desenvolvimento para a atividade, servindo como base de apoio aos turistas. Além do turismo de aventura, foram identificados os demais segmentos, como o turismo científico, turismo religioso, turismo cultural, turismo de natureza.

As atividades do turismo de aventura identificadas, de acordo com a classificação do Ministério do Turismo do Brasil (Brasil, 2010), foram caminhada, caminhada de longo curso e escalada, realizadas em graus de dificuldade leve, médio e alto. Embora oferte apenas três atividades do segmento, esse núcleo assume significativa importância, pois além de sua infraestrutura, possui alguns dos atrativos de destaques no município.

As atividades do segmento são realizadas em importantes atrativos presentes no núcleo, como a Pedra do Cruzeiro o principal afloramento rochoso do centro urbano da cidade, a Pedra do Barney, o Vale Perdido, o Açude do Eurípedes, o Conjunto de monólitos do Eurípedes (Figura 3), a Pedra Cabeça da Bruxa e a Gruta Psicose.

\subsection{Fazenda Magé}

A Fazenda Magé é o núcleo mais próximo da sede municipal, com aproximadamente $4 \mathrm{~km}$ de distância em relação ao centro urbano e os segmentos presentes foram o turismo de aventura, o turismo cultural e o turismo de natureza. Entre os atrativos relacionados ao turismo de aventura, 
encontra-se a árvore centenária, do gênero Ceiba, família Malvaceae, popularmente chamada de barriguda pelos guias que conduzem a principal atividade do núcleo, a Trilha da Barriguda. Outro atrativo de destaque, são os afloramentos rochosos, destacando-se a Pedra Magé, pois neles são realizadas as atividades de escalada (Figura 4).

Em relação a sua infraestrutura, o núcleo oferece o serviço de hospedagem e possui um restaurante que funciona mediante agendamento. Identificou-se a realização de atividades de caminhada, caminhada sem pernoite, cavalgada, cicloturismo, espeleoturismo, escalada e montanhismo, o que faz com que o núcleo se estabeleça como um dos polos com maior variedade de oferta de atividades, as quais são desenvolvidas de acordo com as especificidades de cada público.

\subsection{Bacia do Cedro}

Sua distância em relação ao centro urbano da sede do município é em torno de $6,5 \mathrm{~km}$, os segmentos identificados foram turismo aventura, turismo cultural, turismo de natureza e turismo científico. Nesse núcleo está a principal paisagem associada ao município, a Pedra da Galinha Choca, um importante ponto turístico, sendo inclusive referência para o turismo em geral no Estado do Ceará.

Neste núcleo, na paisagem na qual se insere a Pedra da Galinha Choca, há ainda a barragem do Cedro, que possui grande valor histórico, arquitetônico e cultural, sendo considerada a primeira grande intervenção mitigadora da seca, tendo suas obras iniciadas no século XIX por D. Pedro I.

Seus principais atrativos são a parede da barragem, um galpão centenário, datado da própria construção da barragem e algumas peças ainda preservadas. Por seu potencial, diversos segmentos são desenvolvidos, como o turismo cultural, turismo de natureza, turismo científico e o turismo de aventura.

As atividades de turismo de aventura identificadas foram escalada, caminhada e caminhada sem pernoite. Entre os principais atrativos relacionados ao segmento, está a Pedra da Faladeira (Figura 5), onde se realizam atividades de escalada e rapel, além da Pedra da Galinha Choca, onde se realizam caminhadas, escaladas e rapel. Ainda são atrativos a Pedra do Sapo e a Caverna dos Ventos. $\mathrm{Na}$ infraestrutura deste núcleo não há equipamentos de hospedagem, mas existem restaurantes e quiosques.

\subsection{Morro do Urucum - Santuário Rainha do Sertão}

Distando aproximadamente $11 \mathrm{~km}$ do centro urbano da sede municipal, esse núcleo destacase como o principal ponto de voo livre no município, além de ser um cenário simbólico, com relevante valor para a história do turismo local, pois lá foi instalada a primeira rampa oficial de voo livre (atualmente já existem duas rampas nesse núcleo) e o lugar em que foi realizado o primeiro salto de Quixadá, na década de 1990, considerado o marco que inicia a trajetória do turismo de aventura local. 
Além do turismo de aventura, o núcleo é referência no turismo religioso, pois nele se localiza - Santuário Nossa Senhora Imaculada Rainha do Sertão. Nesse núcleo, são realizados voos de parapente e asa delta (Figura 6). Seus principais atrativos são as rampas de voo que recebem praticantes nacionais e internacionais, assim como é cenário para a realização de eventos e encontros referentes à modalidade.

Embora seja realizada menor quantidade de atividades, esse núcleo é considerado um dos principais, pois é a maior referência na prática de voo livre (parapente e asa delta), assumindo projeção internacional, amplamente conhecido entre os praticantes da modalidade devido aos recordes obtidos em saltos nas rampas de voo presentes nesse núcleo.

\subsection{Juatama}

O distrito de Juatama, com aproximadamente $20 \mathrm{~km}$ do centro urbano da sede municipal, se configura como importante núcleo entre os seis que foram destacados. O distrito possui relevante potencial geomorfológico e histórico para Quixadá. Nele foram identificados os segmentos de turismo de aventura, turismo cultural, turismo científico e turismo de natureza.

Os principais atrativos da área são o conjunto de serrotes, propício para a prática de atividades de aventura, a fauna, especialmente relacionada à diversidade de aves e destacando-se como um distrito que impulsiona o turismo de observação de aves. Ainda se ressalta a vegetação que se encontra bem preservada em algumas áreas, a fazenda Ouro Preto e duas rampas de voo livre, uma delas sendo a única rampa de grama sintética do município (Figura 7).

O ponto de maior referência e que concentra a oferta de atividades do turismo de aventura é o Hotel Pedra dos Ventos, com projeção internacional, sobretudo, em relação ao voo livre. As atividades de turismo de aventura que são ofertadas pelo empreendimento são caminhada, caminhada sem pernoite, escalada, montanhismo, voo livre, canionismo, cicloturismo, além das demais atividades do segmento que se encontra em fase de projeto, como o arvorismo, tirolesa e rafting.

\subsection{Serra do Estevão}

Esse é o núcleo mais distante do centro urbano da sede municipal, com aproximadamente 21 $\mathrm{km}$ e o de maior altitude, com aproximadamente $750 \mathrm{~m}$, além de ser o que se localiza mais próximo aos limites do município, sendo limítrofe com o município de Choró. Os principais segmentos identificados no núcleo foram o turismo de aventura, o turismo de natureza, o turismo científico e o turismo religioso.

Mesmo o núcleo dispondo de um significativo potencial para o turismo de aventura, identificou-se que as principais atividades que são realizadas na área são apenas caminhada e caminhada sem pernoite. Entre os principais atrativos turísticos do núcleo, destaca-se a própria beleza cênica da Serra do Estevão, a vista panorâmica do município (Figura 8), sua geodiversidade e 
biodiversidade, bem como pequenas cachoeiras (em tempos chuvosos), mirante para observação da paisagem, vegetação e fauna.

A Serra do Estevão é um núcleo com significativo potencial para o turismo de aventura e o turismo de natureza, no entanto, observou-se que o núcleo ainda tem grande parte do seu potencial inexplorado e se faz necessário um planejamento voltado para o aproveitamento de suas potencialidades e a implementação de estratégias que possam fomentar o turismo no núcleo.

\subsection{Problemas, limitações e proposições acerca do turismo no município de Quixadá}

Embora os seis núcleos do turismo de aventura que foram identificados tenham relevante potencial turístico e já desenvolvam atividades do segmento, observou-se que outras áreas no município também possuem esse potencial ainda inexplorado. Nesse sentido, a concentração das atividades em seis núcleos se configura como uma limitação que necessita de planejamento adequado, buscando expandir o turismo de aventura para demais localidades, de forma organizada e contextualizada com as potencialidades de cada área. Ainda foram identificados outros problemas que impactam o desenvolvimento do segmento no município.

Considerando que o município é um importante destino e que possui potencial para o turismo de aventura, são sugeridas algumas estratégias voltadas para potencializar o segmento, tendo como a principal sugestão, a elaboração de um plano de gestão integrado às diretrizes de órgão como o Instituto Brasileiro do Meio Ambiente e dos Recursos Naturais Renováveis (IBAMA), o Instituto Chico Mendes de Conservação da Biodiversidade (ICMBIO), Instituições de Ensino Superior, a Secretaria de Turismo do Estado do Ceará (SETUR), a Secretaria de Meio Ambiente (SEMA), Secretarias Municipais (especialmente a Secretaria de Desenvolvimento Urbano e Meio Ambiente; Secretaria de Desenvolvimento Econômico e Turismo), as comunidades locais e empreendedores, tendo como objetivo um desenvolvimento mais contextualizado com a realidade, que possa alcançar os anseios e necessidades das esferas ambiental, social e econômica.

Acredita-se que considerar a inclusão de um planejamento geoturístico e de turismo de aventura no Plano Diretor Municipal, pode se refletir como uma significativa consolidação do desenvolvimento turísticos local, contando com a efetiva contribuição do Poder Público. Por se tratar de um destino que apresenta consideráveis possibilidades turísticas, as estratégias e ações devem ser consideradas a partir de uma dimensão maior e tidas como um caminho para o desenvolvimento local.

A falta de manutenção em alguns dos pontos turísticos do município de Quixadá foi outro problema identificado no decorrer da investigação e como forma de contornar essa adversidade é proposto a intensificação de medidas voltadas para fiscalização e projetos para a revitalização desses pontos, bem como a melhoria de sua infraestrutura como a instalação de banheiros públicos, instalação lixeiras nos locais que ainda não as têm, instalação de restaurantes, construção de museus e demais espaços que proporcione maior comodidade e atenda às necessidades dos visitante. 
A divulgação em fontes midiáticas pode ser uma importante ferramenta que contribui para divulgar e promover destinos turísticos, pois seu poder de alcance é amplo e pode propagar-se para variados públicos em diversos locais, acredita-se que direcionar investimentos na área de divulgação e marketing pode resultar em impactos positivos.

Atualizar e manter canais de informações sobre o turismo local, sobre os segmentos existentes no município, sobre as atividades turísticas que são ofertadas, opções de hospedagens e serviços disponível, materiais temáticos, como mapas, ilustrações, folhetos explicativos sobre as atividades existentes no local (escalda, trilhas, voo livre, entre outros.) são algumas das sugestões para potencializar a divulgação do turismo no município de Quixadá.

A elaboração de material temático atrativo é uma proposição que tem por objetivo disponibilizar opções mais lúdicas e que despertam o interesse do público em visitar os espaços apresentados no material. Sendo assim, a elaboração de cartilhas, panfletos, mapas, ilustrações é recomendada para despertar o interesse do turista e é um meio para a instruir o público sobre diversos assuntos sobre o destino visitado.

Foram identificados espaços de relevante valor cultural e histórico, como o galpão centenário do açude Cedro, contendo peças e maquinários ainda bem preservados, utilizados na construção da barragem e para outros fins, retratando o passado histórico do local.

Os prédios das primeiras ferrovias instaladas no município são apontados como espaços de considerável importância, se encontram bem preservados e simbolizam o avanço dos transportes no município e no estado. Considerando a importância história e cultural desses espaços, se sugere que nele sejam criados espaços culturais e museus, como forma de valorizar a história local.

Outra forma de divulgação importante é aquela realizada em espaços diferenciados, como em escolas e instituições de ensino superior, estimulando a participação de públicos diversos que tenham interesse em buscar o destino não apenas para interação recreativa, mas para vivências que proporcionam a construção de conhecimento e a possibilidade de incluir esse destino em outras perspectivas, como aula de campo escolares, trabalhos acadêmicos e pesquisas científicas.

Ainda é sugerido o incentivo à realização de eventos locais, como a feira do produtor, que pode ser uma estratégia para a dinamização da economia, a valorização dos produtos artesanais confeccionados no município e que tem potencial para se estabelecer como uma atividade cultural para o turismo, pois as feiras são popularmente conhecidas e símbolo da cultura nordestina do Brasil.

O incentivo à fabricação de produtos artesanais, alimentícios, decorativos, de vestuários, entre outros é uma sugestão que pode converter-se em resultados positivos, pois além de serem mercadorias de interesse ao público turístico é uma forma de valorização da cultura local e uma alternativa para potencializar a renda das comunidades envolvidas.

Acredita-se que 0 desenvolvimento turístico deve consolidar-se com medidas conservacionistas, considerando a relevância dos recursos naturais e a própria permanência das práticas turísticas, visto que o ambiente natural é a base para o desenvolvimento dessas práticas. Planejar caminhos turísticos contextualizados com a sustentabilidade ambiental é primordial para a 
sobrevivência dos ecossistemas envolvidos e para a qualidade de vida das comunidades existentes nos destinos turísticos, além de uma pauta de âmbito planetário.

Sendo assim, são sugeridos trabalhos com ênfase na conservação da biodiversidade, como projetos de recuperação e conservação da vegetação caatinga, predominante na área e conhecida por sua fragilidade. Trabalhos voltados para a preservação da geodiversidade, considerando que essa é característica que se sobrasai na natureza do município de Quixadá e que exerce significativa relação com o turismo, além de iniciativas voltadas para a geoeducação como forma de sensibilizar o turista para as particularidades do meio ambiente.

\section{Considerações finais}

A combinação entre os elementos da geodiversidade do município, juntamente com a riqueza de sua biodiversidade, torna Quixadá um polo turístico de relevante potencial no semiárido cearense, um cenário diferenciado para as práticas de atividades do turismo de aventura e demais segmentos. Apesar de identificados seis núcleos turísticos, percebe-se que no município, há diferentes localidades que apresentam características propícias para desenvolver o segmento e que expandir essas atividades podem se converter em resultados positivos para as comunidades.

No entanto, mesmo diante de sua potencialidade, para que haja um desenvolvimento efetivo, continuado, primando pela conservação ambiental e pela qualidade de vida das comunidades locais, se faz necessário considerar que o turismo é uma atividade que necessita de planejamento e acompanhamento adequados, visando maximizar seus aspectos positivos e minimizar os possíveis problemas e conflitos gerados, pois se trata de uma atividade econômica e que gera impactos no meio em que se estabelece.

Criar estratégias e mecanismos de planejamento e monitoramento das atividades turísticas pode auxiliar na própria continuidade e qualidade do fenômeno turístico. Planejar o desenvolvimento turístico considerando as especificidades do meio ambiente pode se converter em uma estratégia de conservação dos próprios recursos naturais.

\section{Agradecimentos}

A efetivação desta pesquisa contou com o significativo apoio da Coordenação de Aperfeiçoamento de Pessoal de Nível Superior (CAPES), do Programa de Desenvolvimento e Meio Ambiente (PRODEMA-UFC) e do Laboratório de Geoecologia da Paisagem e Planejamento Ambiental no Departamento de Geografia da Universidade Federal do Ceará.

\section{Referências}

Borba, A. W. de. (2010). Geodiversidade, patrimônio geológico, geoconservação: conceitos emergentes para uma nova geração de geólogos. Conselho em Revista, 6, p. 32-32.

Brasil. (2010). Ministério do Turismo: Turismo de Aventura: Orientações Básicas. Brasília. Ministério do Turismo

Brilha, J. (2005). Património Geológico e Geoconservação: a conservação da natureza na sua vertente geológica. Braga. Editora Palimage Editores. 
Brion, N. H. D. A. (2016). Cadeia Hoteleira em Quixadá: Hospedagem de Turistas Estrangeiros Falantes de Inglês. In: Silva, L.; Pereira, A. Q.; Amaral, E. L. G. do. Sertão Central Cearense: turismo, meio ambiente e desenvolvimento regional. Recife. Editora Imprima.

Camelo, H. do N Carvalho, P. C. M. Leal-Junior. J. B. V. Accioly-Filho, J. B. P. (2008). Análise estatística da velocidade de vento do estado do Ceará. Revista Tecnol, 29, p.211-223.

Ceará. (2017). Instituto de Pesquisa e Estratégia Econômica do Ceará. Perfil básico do município de Quixadá, Ceará, Disponível em: https://www.ipece.ce.gov.br/wpcontent/uploads/sites/45/2018/09/Quixada_2017.pdf. Acesso 13/03/2020 às 14:30.

Coriolano, L. N. M. T.; Morais, E. O. de. (2011). Desvendando Caminhos do Turismo de Aventura no Brasil. Revista Iberoamericana de Turismo-RITUR. 1. p. 3-11.

Dantas, L. M. R.; Pires, P. dos S. (2015) Versões e contradições do Turismo de Aventura: reflexões sobre as atividades de aventura e sobre o turista. Turismo e Sociedade, 8, p. 276-300.

Lima, R. J. R. Crispim, A. B. Souza, M. J. N. (2016). Relação entre o Relevo e o Uso da Terra do Município de Quixadá - Ceará. Espaço Aberto: Revista do Programa de Pós Graduação em Geografia, 6. p. 73-88.

Moreira, J. C. (2014). Geoturismo e interpretação ambiental. Ponta Grossa. Editora UEPG.

Paiva, O. G., Coutinho, C. M. P. Junior, R. D. (2006). Monólitos de Quixadá: patrimônio de todos: roteiro do Patrimônio Cultural. Fortaleza. IPHAN.

Pereira, R. G. F. de A. Rios, D. C. Garcia, P. M. P. (2016). Geodiversidade e Patrimônio Geológico: ferramentas para a divulgação e ensino das geociências. Revista Terra e Didática, 12. p. 196208.

Rodriguez, J. M.; Silva, E. V. (2013). Planejamento e gestão ambiental: subsídios da geoecologia das paisagens e da teoria geossistêmica. Fortaleza. Edições UFC.

Serrano, E. Ruiz-Flaño, P. (2007). Geodiversidad: concepto, evaluación y aplicación territorial. El caso de tiermes caracena (soria). Boletín de La Asociación de Geógrafos Españoles. 45. p. 79-98.

Silva, C. A. V. da. (2017). Há "pedras" no meu curral: a paisagem dos monólitos de Quixadá-CE. (Dissertação de Mestrado). Instituto do Patrimônio Histórico e Artístico Nacional -IPHAN. Mestrado Profissional em Preservação do Patrimônio Cultural. Rio de Janeiro. $195 f$.

Vasconcelos, F. P.; Silva, A. C. P.; Costa, L. F. da. (2012). Turismo de aventura e ecoturismo: entre práticas e normas no contexto brasileiro. Revista Iberoamericana de Turismo - Ritur. 2, p.108138.

Swarbrooke, J. (2000). Turismo Sustentável: conceitos e impacto ambiental. São Paulo. Editora Aleph.

Swarbrooker, J. (2003). Turismo de Aventura: Conceitos e Estudos de Casos. Rio de Janeiro. Editora Campus 


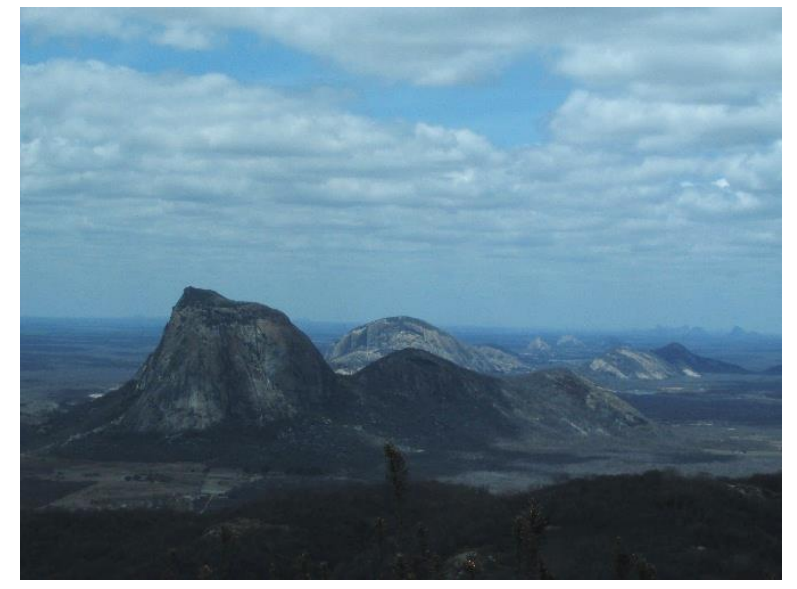

Figura 1: Campos de inselbergs no município de Quixadá.

Fonte: Os autores (2019).

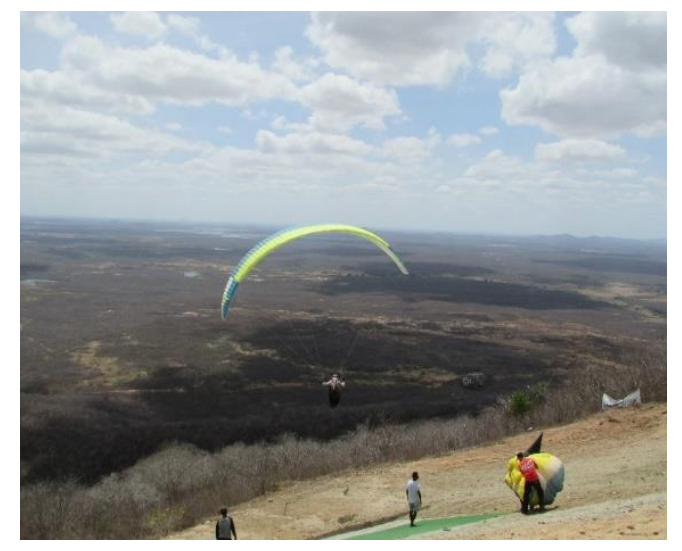

Figura 2: Voo livre no município de Quixadá.

Fonte: Os autores (2018).

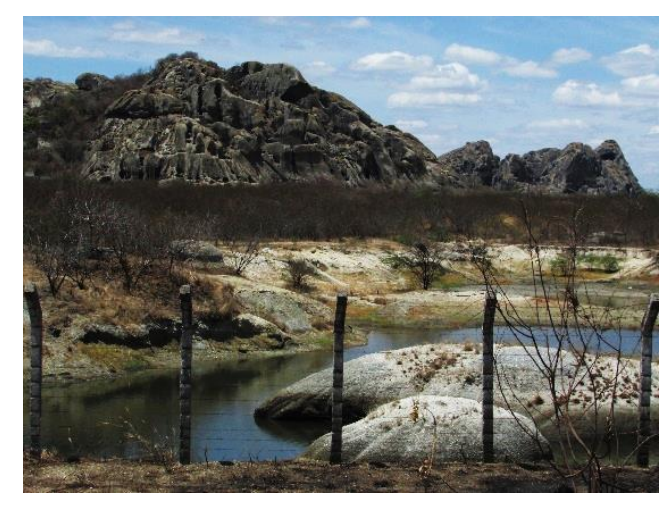

Figura 3 - Conjunto de monólitos do Eurípedes.

Fonte: Os autores (2019). 


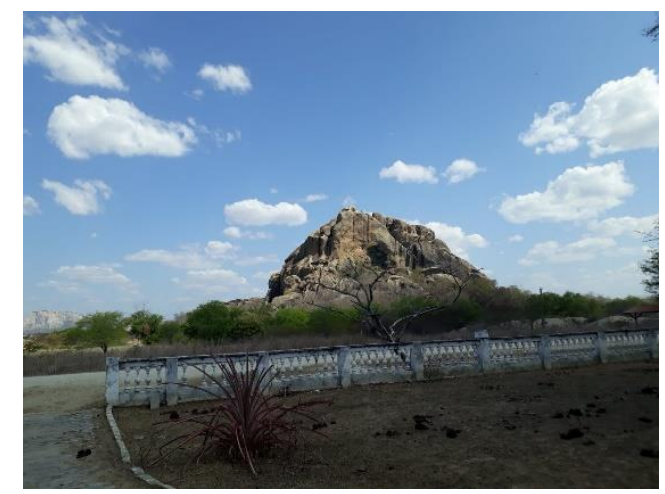

Figura 4 - Afloramento rochoso na Fazenda Magé em Quixadá.

Fonte: Os autores (2019).

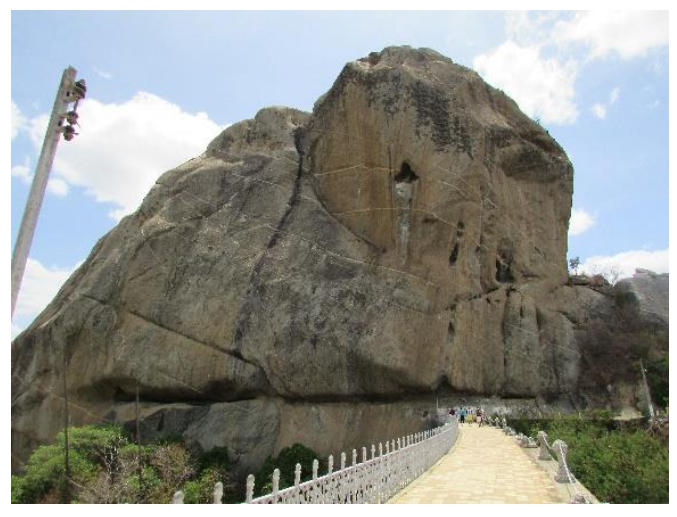

Figura 5 - Pedra da Faladeira na barragem do açude Cedro.

Fonte: Os autores (2019).

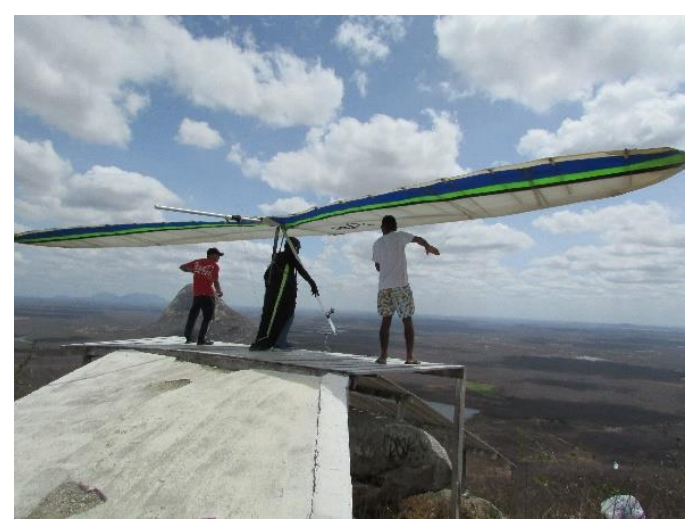

Figura 6: Voo de asa delta da rampa do Santuário em Quixadá. 
Fonte: Os autores (2019).

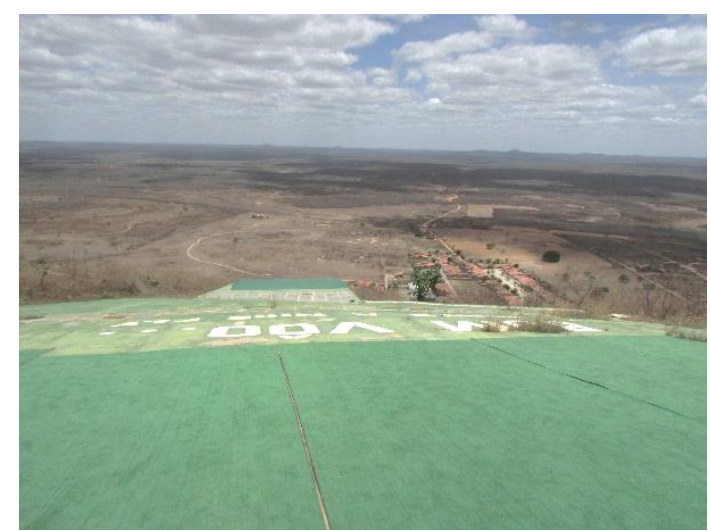

Figura 7 - Rampa de voo livre em Juatama-Quixadá.

Fonte: Os autores (2019).

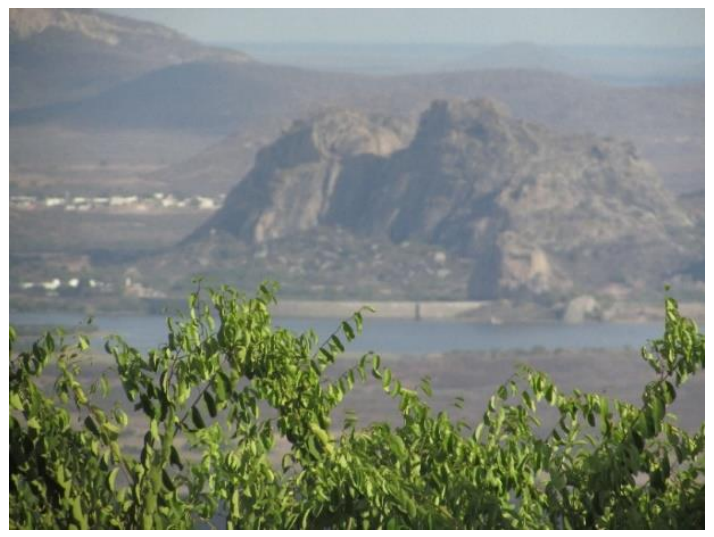

Figura 8 - Vista panorâmica do alto da Serra do Estevão - Quixadá.

Fonte: Os autores (2019). 
